() Н.В. Молашенко*, Е.А. Трошина, Д.М. Бабаева, Л.В. Никанкина, Н.М. Малышева, Ф.А. Бостанова

Национальный медицинский исследовательский центр эндокринологии, Москва, Россия

ОБОСНОВАНИЕ. Аутоиммунный полигландулярный синдром (АПС) характеризуется поражением двух и более эндокринных желез, приводящим со временем к развитию их гормональной недостаточности. В некоторых клинических наблюдениях описано развитие поражения миокарда на фоне сочетанной аутоиммунной эндокринной патологии. Впервые в РФ проведено обследование состояния миокарда у взрослых пациентов с АПС 2, 3 типов.

ЦЕЛЬ. Оценить структуру и функциональное состояние миокарда по данным магнитно-резонансной томографии (МРТ), провести анализ изменений спектра специфических аутоантител к миокарду и маркеров его повреждения у пациентов с АПС 2, 3 типов.

МЕТОДЫ. Обследовано 50 пациентов с АПС 2, 3 типов. 45 из них проведена МРТ сердца с отсроченным контрастированием. Всем 50 пациентам методом непрямого иммуноферментного анализа (ИФА) проведено определение антител IgG к антигенам сердечной мышцы, методом иммунохемилюминесцентного анализа (ИХЛА) - тропонина I, натрийуретического пептида, методом NAC (N-ацетил-L-цистеин) - креатинфосфокиназы (КФК), методом иммунотурбидиметрии - С-реактивного белка (СРБ).

РЕзУЛЬтАТЫ. По результатам МРТ сердца (n=45) у 91\% выявлены признаки функциональных изменений миокарда левого желудочка (ЛЖ), признаков миокардита не выявлено. У 38 из 45 обследованных определялось отклонение 2 и более показателей функционального состояния ЛЖ, $\mathrm{M}_{\Phi \mathbf{B}} 68,9 \pm 6,6 \%, \mathrm{Me}_{\mathrm{Mm}}-86[75 ; 99]$ г, Mе $\mathrm{yo}_{\mathrm{o}}-60,9[50 ; 66]$ мл, $\mathrm{Me}_{\text {кдои }}-52[44 ; 59]$ мл/м², Mе ксои $-17[15,3 ; 18]$ мл/м², $\mathrm{Me}_{\text {ксо }}-26[23 ; 31]$ мл, Ме кдо - 85 [70; 92] мл. По данным определения антител (АТ) к антигенам (АГ) сердечной мышцы положительный результат выявлен у 1 пациента (2\%). Показатели тропонина 1 не превышали референсных значений. Уровень КФК превысил референсные значения у 3 пациентов (6\%), повышение СРБ, NT-proBNP отмечено у 7 пациентов (14\%), из них сочетанное повышение в 1 случае.

ЗАКЛючЕНИЕ. У пациентов С АПС 2, 3 типов получены МРТ-данные, свидетельствующие о функциональных изменениях миокарда. Аутоиммунная причина данных изменений по результатам определения АТ к миокарду не подтверждена у большинства обследованных пациентов, показатели «повреждения» миокарда (тропонин 1 и NT-proBNP) не имели отклонений от референсного диапазона.

КЛЮЧЕВЫЕ СЛОВА: аутоиммунный полигландулярный синдром, миокардит, антитела к миокарду, МРТ сердиа.

\title{
INSTRUMENTAL AND LABORATORY PARAMETERS OF MYOCARDIAL FUNCTION IN ADULT PATIENTS WITH AUTOIMMUNE POLYGLANDULAR SYNDROME TYPE 2, 3
}

\author{
(c) N.V. Molashenko*, E.A. Troshina, D.M. Babaeva, L.V. Nikankina, N.M. Malysheva, F.A. Bostanova
}

Endocrinology Research Centre, Moscow, Russian Federation

BACKGRAUND: Autoimmune polyglandular syndrome (APS) it is characterized by damage to two or more endocrine glands, which eventually results in the hormonal failure. Some clinical studies describe the development of myocardial lesion in the setting of combined autoimmune endocrine pathology. In Russia the myocardial condition in adult patients with APS types 2 and 3 was examined for the first time.

AIM: To evaluate the structure and functional state of the myocardium according to magnetic resonance imaging (MRI), to analyze changes in the spectrum of specific antiheart autoantibodies and markers of heart lesion in patients with APS types 2 and 3.

MATERIALS AND METHODS: 50 patients with APS types 2, 3 were studied. 45 of them were performed with delayed contrast heart MRI. All 50 patients were tested for lgG antibodies to heart muscle antigens by indirect enzymatic immunoassay (EIA), for troponin I and natriuretic peptide by chemiluminescence immunoassay (CLIA), for creatine phosphokinase (CPK) by NAC ( $\mathrm{N}$ - acetyl-L-cysteine), and for C-reactive protein (CRP) by immunoturbidimetry. 
RESULTS: According to the results of heart MRI ( $n=45), 91 \%$ showed signs of functional changes in the left ventricular (LV) myocardium without any signs of myocarditis. 38 of 45 examined patients had deviation of 2 or more indicants of the LV functional state, $\mathrm{M}_{\mathrm{EF}} 68.9 \pm 6.6 \%, \mathrm{IU}_{\mathrm{Mm}}-86[75 ; 99] \mathrm{g}, \mathrm{IU}_{\mathrm{SV}}-60.9[50 ; 66] \mathrm{ml}, \mathrm{IU}_{\mathrm{EDVi}}-52[44 ; 59] \mathrm{ml} / \mathrm{m}^{2}, \mathrm{IU}_{\mathrm{ESVi}}-17[15.3 ; 18] \mathrm{ml} / \mathrm{m}^{2}$, $\mathrm{IU}_{\mathrm{ESV}}-26[23 ; 31] \mathrm{ml}, \mathrm{IU} \mathrm{EDV}_{\mathrm{EV}}-85[70 ; 92] \mathrm{ml} .1$ patient $(2 \%)$ had positive result according to the determination of antibodies $(A B)$ to heart muscle antigens (AG). Troponin 1 indicants did not exceed the reference values. The level of CPK exceeded the reference values in 3 patients (6\%), an increase of CRP, NT-proBNP was observed in 7 patients (14\%), and a combined increase was observed in 1 case.

CONCLUSIONS: We obtained MRI data indicating functional changes in the myocardium in patients with APS types 2 and 3. The autoimmune cause of these changes according to the results of determining of antiheart antibodies was not confirmed in most of the examined patients, the indicants of «damage» to the myocardium (troponin 1 and NT-proBNP) did not deviate from the reference range.

KEYWORDS: autoimmune polyglandular syndromes, myocarditis, antibodies to a myocardium, MRI of the heart.

\section{ОБОСНОВАНИЕ}

Аутоиммунный полигландулярный синдром взрослых (АПС) характеризуется поражением двух и более эндокринных желез, приводящим со временем к развитию их гормональной недостаточности. В состав АПС, помимо поражения органов эндокринной системы, может входить аутоиммунное поражение других органов.

АПС 2, 3 типов - полигенное заболевание. У пациентов с рождения существует генетическая предрасположенность к аутоиммунному поражению ткани в результате наличия специфических генов системы HLA (например, DR3, DR4, B8, DQA1). AПС 2 типа, как правило, характеризуется наличием первичной хронической надпочечниковой недостаточности (1-ХНН) и аутоиммунного поражения щитовидной железы - болезни Грейвса (БГ) или гипотиреоза в исходе аутоиммунного тиреоидита (АИТ). АПС 3 типа - это сочетание аутоиммунных поражений, исключая 1-ХНН и гипопаратиреоз. Зачастую, если у пациента есть одно аутоиммунное заболевание, другие составляющие АПС проявляются после латентного периода [1].

В основе патогенеза АПС 2, 3 типов лежит лимфоидная и макрофагальная инфильтрация органа-мишени в результате нарушения Т-клеточного иммунитета, дефекта регуляторных Т-лимфоцитов. Возникают деструкция ткани органа-мишени и гормональная недостаточность. В-лимфоциты при АПС продуцируют аутоантитела чаще всего к ферментам, участвующим в синтезе гормонов [1, 2].

Поражение миокарда не выделено в состав АПС, но в некоторых клинических наблюдениях описано его развитие на фоне сочетанной аутоиммунной эндокринной патологии. На сегодняшний день достаточно много работ посвящено поражению миокарда при аутоиммунных заболеваниях щитовидной железы, особенно БГ, в меньшей степени изучена проблема при ХНН или сахарном диабете 1 типа. Изменения миокарда при тиреотоксикозе аутоиммунной природы могут быть связаны с аутоиммунным миокардитом, хотя механизмы, лежащие в основе развития данного состояния, до конца не изучены. У пациентов с аутоиммунными причинами гипо- и гипертиреоза дегенерация клапанного аппарата сердца встречается до 25 и 35\% случаев соответственно, при многоузловом токсическом зобе - в 7,5\% [3-5].
В литературных источниках описан высокий процент сопутствующих аутоиммунных заболеваний у больных миокардитом: в 19\% случаев при гигантоклеточном миокардите, в 11\% случаев - морфологически верифицированном миокардите, таким образом, возможно, нарушение именно аутореактивности является причиной развития воспалительных заболеваний миокарда [6]. Описаны его сочетания с болезнью Крона (Cooper et al., 1995, 1997), неспецифическим язвенным колитом (Cooper et al., 1997; Ariza et al., 1995; McKeon 1986), миозитом opбитальных мышц и скелетной мускулатуры (Leib et al., 1994; Klein et al., 1998), АИТ (Benish and Josephson, 1973; Davies et al., 1975) и артериитом Такаясу (Kennedy et al., 1971; Roberts 1966), ревматоидным артритом, тотальной алопецией.

Распространенность легких или латентных форм миокардита установить трудно, так как заболевание может протекать бессимптомно [7].

Лабораторная диагностика миокардита проводится с помощью определения антител (АТ) к антигенным структурам сердца, С-реактивного белка (СРБ), MB-изоформы креатинкиназы, цитокинового профиля (интерлейкин-10, фактор некроза опухоли альфа (ФНО-а)) [8-10]. Хотя инструментальная диагностика миокардита - сложный процесс, магнитно-резонансная томография (МРТ) доказала свою высокуюдиагностическую значимость, независимо от причины заболевания [11]. Цель исследования - оценить структурно-функциональное состояние миокарда у взрослых пациентов с АПС, имеющих различные аутоиммунные компоненты заболевания, определить наличие у них признаков пограничного или манифестного миокардита.

\section{МЕТОДЫ}

\section{Дизайн исследования}

Проведено одноцентровое одномоментное выборочное неконтролируемое исследование.

\section{Критерии соответствия}

В исследование включались пациенты с верифицированным АПС 2, 3 типов 18-55 лет. Условием включения являлось подписание информированного согласия на участие в исследовании. 
Критерии невключения/исключения: наличие в анамнезе острого инфаркта миокарда, кардиомиопатии иного генеза, тяжелые сопутствующие заболевания (декомпенсация хронической сердечной недостаточности, хроническая обструктивная болезнь легких, почечная, печеночная недостаточность), онкологические заболевания в анамнезе, период беременности и лактации.

\section{Условия проведения}

Набор группы пациентов с АПС взрослых проводился среди пациентов-славян, имеющих различные комбинации эндокринных и неэндокринных заболеваний аутоиммунного генеза, находящихся на стационарном лечении в ФГБУ «НМИЦ эндокринологии» Минздрава России. Способ формирования выборки - сплошной набор.

\section{Продолжительность исследования}

Исследование продолжалось с января 2017 г. по июль 2020 г.

\section{Описание медицинского вмешательства}

У всех пациентов, включенных в исследование, проводились биохимические и иммунологические анализы крови: определение AT IgG к антигенам (АГ) сердечной мышцы, общей фракции креатинфосфокиназы (КФК), СРБ, тропонина I, натрийуретического пептида (N-терминального фрагмента натрийуретического мозгового пропептида, NT-proBNP). 45 пациентам проведено MPТ сердца с отсроченным контрастированием.

\section{Основной исход исследования}

«Суррогатными конечными точками» исследования являлись наличие/отсутствие АТ к антигенам сердечной мышцы, показатели состояния миокарда по результатам МРТ: фракция выброса (ФВ) левого желудочка (ЛЖ), \%, масса миокарда ЛЖ (Mm), г, ударный объем сердца (УО), мл, индекс конечного диастолического объема ЛЖ (КДОИ), мл/м², индекс конечного систолического объема ЛЖ (КСОИ), мл/М², конечный систолический объем ЛЖ сердца (КСО), мл, конечный диастолический объем Лж сердца (КДО), мл, размеры предсердий сердца, мм, визуальная оценка характера накопления контрастного вещества миокардом для выявления очаговых и диффузных воспалительных и фиброзных изменений, характерных для миокардита, в виде появления зон отека и накопления контрастного вещества в отсроченную фазу.

Дополнительные исходы исследования

Для оценки маркеров «повреждения миокарда» проведено исследование концентрации в крови пациентов с АПС общей фракции КФК, Ед/л, СРБ, мг/л, тропонина I, нг/мл, NT-proBNP, пг/мл.

\section{Анализ в подгруппах}

В ходе исследования методом сплошного набора сформирована и обследована одномоментно 1 группа пациентов из 50 человек с верифицированным диагнозом АПС 2, 3 типов.

\section{Методы регистрации исходов}

Определение антител IgG к антигенам сердечной мышцы проводилось методом непрямого иммунофлюо- ресцентного анализа (CMF IFA, Medipan, Германия), уровни общей фракции КФК исследовали методом NAC (N-ацетил-L-цистеин), фотометрия при 340 нм, реагент Creatine Kinase (Abbott Diagnostics, США), на биохимическом автоматическом анализаторе Architect c8000, референсный интервал (РИ) (30-200), СРБ - методом иммунотурбидиметрии на анализаторе Abbott Architect c8000, реагенты и калибраторы Abbott Diagnostics, США, PИ (0,1-5), тропонина I и NT-proBNP - методом электрохемилюминесцентного иммуноанализа с использованием стандартных коммерческих наборов Elecsys Troponin T hs STAT (Германия) и Elecsys proBNPII (Германия) на иммунохимическом автоматическом анализаторе Cobas 6000, РИ $(0-0,03)$ и $(0-125)$ соответственно.

MPT проводилась на аппарате General Electric Optima MR450w 1.5 T (General Electric Healthcare, USA) с использованием поверхностной кардиальной радиочастотной катушки, с применением контрастного вещества с содержанием активного вещества гадобутрола 1 ммоль/мл, в дозировке 0,15 мл/кг для отсроченного контрастирования. Синхронизация с сердечным ритмом проводилась в стандартных VCG отведениях. Исследование пациентов выполнялось в стандартных плоскостях (по короткой оси, четырехкамерной оси, двухкамерной оси), а также выводящих трактов левого и правого желудочков, с применением последовательностей с кинопетлей во время задержек дыхания. Для расчета стандартных функциональных показателей ЛЖ: ФВ, УО, КДО, КСО, индексы КДО и КСО, Mm ЛЖ использовалась программа постобработки Cardiac VX рабочей станции AW GE Healthcare. MPT сердца выполнялась всем пациентам с отсроченным контрастированием (10-15 минут от начала введения контрастного вещества). Визуализация отека миокарда желудочков проводилась при помощи последовательностей Т2-взвешенных изображений (T2-BИ) «black blood» с подавлением и без подавления сигнала от жировой ткани в плоскостях короткой оси и в 4-камерной плоскости.

\section{Этическая экспертиза}

Локальный этический комитет при ФГБУ «НМИЦ эндокринологии» Минздрава России постановил одобрить возможность проведения Гранта РНФ № 17-75-30035 «Аутоиммунные эндокринопатии с полиорганными поражениями: геномные, постгеномные и метаболомные маркеры. Генетическое прогнозирование рисков, мониторинг, ранние предикторы, персонализированная коррекция и реабилитация» (протокол заседания № 17 от 27.09.17).

\section{Статистический анализ}

Принципы расчета размера выборки: потенциальная репрезентативность выборки оценивалась по отношению к таковой в европейской популяции. Репрезентативность по отношению к российской популяции выявить не удалось в связи с отсутствием эпидемиологических исследований по данной теме.

\section{Методы статистического анализа данных}

Статистический анализ проводился на ПЭВМ с использованием пакета прикладных программ Statistica (StatSoft, USA, версия 13.3). Проверка на нормальность распределения данных выполнялась с помощью критерия ШапироУилка. Для параметров с нормальным распределением 
Таблица 1. Характеристика группы пациентов с аутоиммунным полигландулярным синдромом 2, 3 типов.

\begin{tabular}{|c|c|}
\hline Показатели группы пациентов ( $\mathrm{n=50)}$ & Значение \\
\hline Возраст, годы, Ме [X1/4; X3/4] & $39,5[29 ; 53]$ \\
\hline Число мужчин в группе, n (\%) & $9(18)$ \\
\hline Число женщин в группе, n (\%) & $41(82)$ \\
\hline Число пациентов с ХНН как компонента АПС, n (\%) & $45(90)$ \\
\hline Длительность первичной ХНН, годы, Ме [X1/4; X3/4] & $5[3 ; 10]$ \\
\hline $\begin{array}{l}\text { Дозы препаратов глюкокортикостероидов в заместительной терапии первичной XНH, в пересчете } \\
\text { на гидрокортизон, мг, Ме }[\text { X1/4; X3/4] }\end{array}$ & $20[15 ; 30]$ \\
\hline Число пациентов без ХНН как компонента АПС, n (\%) & $5(10)$ \\
\hline Число пациентов с ревматологическими заболеваниями как компонента АПС, n (\%), & $2(4)$ \\
\hline $\begin{array}{l}\text { Число пациентов с первичным гипотиреозом вследствие аутоиммунного тиреоидита } \\
\text { как компонента АПС, n (\%) }\end{array}$ & $42(84)$ \\
\hline Число пациентов с диффузным токсическим зобом как компонента АПС, n (\%) & $5(10)$ \\
\hline Число пациентов с сахарным диабетом 1 типа как компонента АПС, n (\%) & $2(4)$ \\
\hline Число пациентов с витилиго как компонента АПС, n (\%) & $4(8)$ \\
\hline
\end{tabular}

рассчитывали среднюю величину (M) \pm стандартную ошибку средней $(\mathrm{m})$, количественные признаки, не имеющие приближенно нормального распределения, описывались в виде медианы и нижнего и верхнего квартилей, Ме [X1/4; X3/4].

\section{РЕЗУЛЬТАТЬ}

\section{Объекты (участники) исследования}

Характеристика группы пациентов с АПС 2, 3 типов (всего 50 человек) представлена в таблице 1.

\section{Основные результаты исследования}

Всем 50 пациентам с АПС 2, 3 типов проведено определение уровня АТ к антигенам (АГ) сердечной мышцы. У 49 обследованных (98\%) результат был отрицательным. В одном случае (2\%) выявлены положительные АТ к АГ

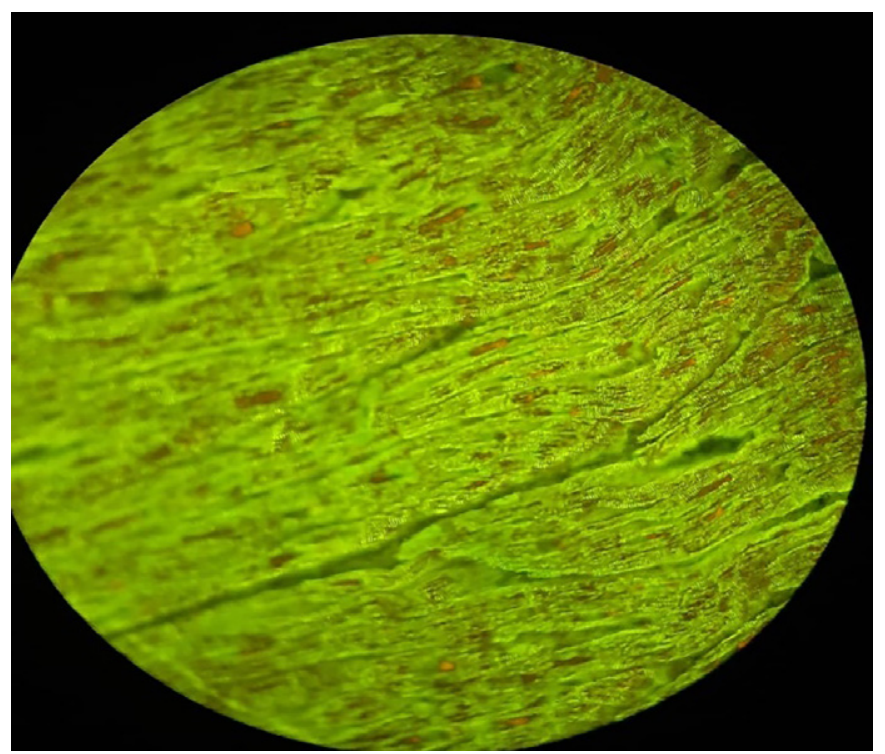

А. Положительный результат $(\mathrm{n}=1)$ сердечной мышцы (рис. 1). У пациента имелось сочетание 1-ХНН первичного гипотиреоза и ревматологический компонент (дерматомиозит). У пациента, несмотря на среднестатистические росто-весовые показатели (рост 178 см, вес 80 кг, ИМТ 27,8 кг/м²), по результатам МРТ сердца имелись особенности: размеры сердца были ниже нормальных значений и большинство функциональных показателей имели отклонение от референсного интервала:УО - 38 мл (60-116), КДОИ 30 мл/м² (61-95), КСОИ 11,7 мл/м² (17-35), КДО 63 мл (90-174), КСО 25 мл (25-63), левое предсердие (ЛП) 44×29 мм (41-69/31-51), правое предсердие (ПП) 45×37 (43-67/36-58), Mm 93 г (70-142), ФВ 60\%. После введения контрастного препарата в отсроченную фазу накопления контрастного препарата не выявлено, что свидетельствует об отсутствии рубцового, фиброзного, воспалительного изменения миокарда.

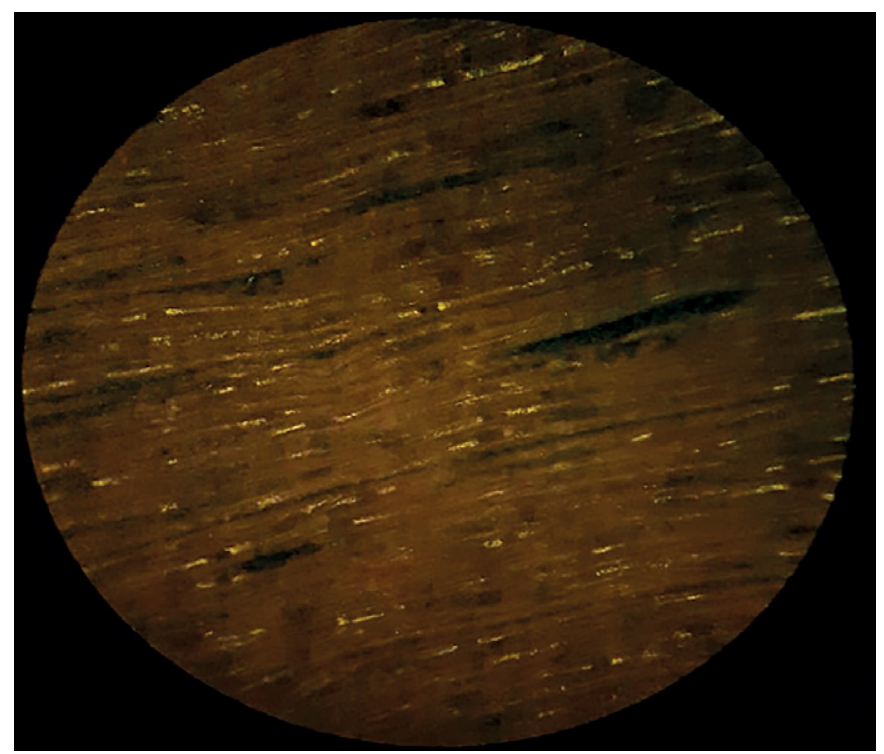

Б. Отрицательный результат $(\mathrm{n}=49)$

Рис. 1. Результаты определения антител к антигенам сердечной мышцы у пациентов с аутоиммунным полигландулярным синдромом 2, 3 типов $(\mathrm{n}=50)$ методом непрямого иммунофлюоресцентного анализа. В 1 случае (А) выявлен положительный результат, в 49 случаях (Б) антитела не определялись. 
Таблица 2. Основные МРТ-характеристики исследования сердца у пациентов с аутоиммунным полигландулярным синдромом 2, 3 типов $(n=45)$

\begin{tabular}{c} 
Значение, \\
Показатель \\
{$[\mathrm{X1/4;}$ X3/4] либо $\mathrm{M} \pm \mathrm{m}, \mathrm{min} / \mathrm{max}$} \\
\hline
\end{tabular}

\begin{tabular}{|c|c|}
\hline$\Phi \mathrm{B}, \%$ & $68,9 \pm 6,6, \min 59 \max 85$ \\
\hline$M_{m^{\prime}}, \Gamma$ & $86[75 ; 99], \min 54 \max 124$ \\
\hline УО, мл & $60,9[50 ; 66], \min 31 \max 98$ \\
\hline КДОИ ${ }_{л ж^{\prime}}$ мл/м & $52[44 ; 59], \min 26,7 \max 76$ \\
\hline $\mathrm{KCOИ}_{л ж^{\prime}} \mathrm{M} / \mathrm{M}^{2}$ & $17[15,3 ; 18], \min 9,4 \max 26,4$ \\
\hline КСО,мл & $26[23 ; 31], \min 9,4 \max 53,2$ \\
\hline КДО, мл & $85[70 ; 92], \min 51,9 \max 146$ \\
\hline ЛП, мм & $\begin{array}{l}\text { поперечный } 48 \text { [41; 53], min } 30 \max 65 \\
\text { переднезадний } 40 \text { [35; 43], } \min 29 \max 51\end{array}$ \\
\hline ПП, мм & $\begin{array}{l}\text { поперечный } 48 \text { [44; 52], min } 33 \text { max } 63 \\
\text { переднезадний } 41 \text { [38; 44], min } 20 \text { max } 55\end{array}$ \\
\hline
\end{tabular}

Данные по показателям МРТ сердца, проведенного 45 пациентам с АПС 2, 3 типов, представлены в таблице 2. Среди обследованных лиц у 91\% пациентов выявлены признаки функциональных изменений миокарда левого желудочка, признаков перенесенного или текущего миокардита сердца не выявлено. У 38 из 45 обследованных (84\%) определялось отклонение 2 и более показателей функционального состояния миокарда ЛЖ. Снижение показателей УО сердца ниже референсного интервала определялось у 19 пациентов (42\%), КДО лж - у 36 человек (80\%), КСО ЛЖ - у 22 пациентов (49\%), КДОИ Лж сердца - у 29 пациентов (64\%), КСОИ Лж сердца у 13 обследованных (29\%). Увеличения размеров камер сердца выявлено не было.

\section{Дополнительные результаты исследования}

Дополнительно в группе пациентов с АПС 2, 3 типов определялись показатели, которые можно отнести к параметрам диагностики воспалительного процесса миокарда и его функционального резерва. Медиана общей фракции КФК составила $\mathrm{Me}_{(\text {(кк) }} 56,5$ [39; 90], $\min 27, \max 251$, отклонение показателя выше референсного интервала определялось у 3 пациентов (6\% случаев). При определении СРБ в 14\% случаев (7 пациентов) выявлялось его повышение, максимально до 9 мг/л, в одном случае - в сочетании с повышением общей фракции КФК, в 1 случае - с повышением NT-proBNP, Me $_{\text {(СРБ) }} 1,65[0,7 ; 3,8], \min 0,2, \max 9,0$. Показатели тропонина I не превышали референсные значения ни в одном случае, $\mathrm{M}_{(\mathrm{T})} 0,007 \pm 0,003$, min 0,004, $\max$ 0,018. Повышение NT-proBNP выявлено у 7 пациентов (14\%), $\mathrm{Me}_{\text {(NT-proBNP) }} 19,4$ [5; 83], $\min 5, \max 247,1$.

Нежелательные явления

Нежелательные явления отсутствовали.

\section{ОБСУЖДЕНИЕ}

Резюме основного результата исследования

По результатам проведенного инструментально-лабораторного обследования состояния миокарда у пациентов с АПС 2, 3 типов получены МРТ-показатели, свидетельствующие о его функциональных изменениях (в 91\% случаев), убедительных данных за аутоиммунную причину выявленных изменений по результатам определения АТ к миокарду не получено (у большинства обследованных пациентов (98\%) - результат анализа отрицательный). Биохимические маркеры «повреждения» миокарда (КФК, тропонин I, СРБ) и сердечной недостаточности (натрийуретический пептид) в $72 \%$ случаев $(n=36)$ не превышали референсные значения, изолированное повышение показателей КФК, СРБ, NT-proBNP определялось у 6-14\% обследованных, повышение 2 показателей в 4\% случаев $(\mathrm{n}=2)$.

Обсуждение основного результата исследования

В РФ впервые проведено обследование состояния сердца у взрослых пациентов с АПС, большинство из которых имели 1-ХНН как компонент заболевания. На момент обследования состояния миокарда все пациенты были компенсированы по имеющимся у них компонентам АПС. В литературе имеются единичные описания случаев фатального поражения миокарда при ХНH. Так, в статье A. Sezai, M. Hata приведен клинический пример сочетания гипертрофической кардиомиопатии, потребовавшей хирургического вмешательства у пациента с синдромом Шмидта [12]. Nielsen и соавт. описали случай развития прогрессировавшей аутоиммунной кардиомиопатии у 32-летнего мужчины с АПС 2 типа, потребовавшей пересадки сердца [13]. В литературных источниках есть примеры развития кардиомиопатии Такоцубо и гигантоклеточного миокардита на фоне АПС, в клинической картине которых превалировала надпочечниковая недостаточность [14-16].

Много работ посвящено исследованию миокарда у пациентов с гипертиреозом. В качестве основного инструментального метода многие авторы выбирают МРТ сердца. Для диагностики воспалительных заболеваний миокарда используют МРТ с поздним контрастным усилением, когда исследование проводят через 15-20 минут после введения контрастного вещества. В норме миокард быстро накапливает и равномерно выводит контрастное вещество. Если в отсроченную фазу мы видим наличие контраста в ткани, это свидетельствует о фибротических процессах в миокарде $[11,17,18]$.

Золотым стандартом, позволяющим верифицировать диагноз миокардита на основании гистологических и иммуногистохимических критериев, по рекомендациям Национального общества по изучению сердечной недостаточности и заболеваний миокарда (2016 г.), по-прежнему остается эндомиокардиальная биопсия. В связи с риском развития осложнений при проведении эндомиокардиальной биопсии широкое ее применение в клинической практике ограничено.

B статье Mavrogeni S. и соавт. было проведено обследование 250 пациентов с тиреотоксикозом, 
у 15 (6\%) из них по результатам МРТ и эндомиокардиальной биопсии было подтверждено наличие аутоиммунного миокардита. В работе Fatourechi V. и соавт. 11 пациентам с БГ проводилась биопсия миокарда, в 18\% случаев выявлена лимфоидная инфильтрация, верифицирующая аутоиммунное поражение миокарда $[19,20]$.

По нашим данным, мы не выявили ни одного случая миокардита у пациентов с АПС 2, 3 типов. Возможно, это связано с размером выборки (50 человек), только 5 человек имели диффузный токсический зоб в анамнезе (10\% пациентов). Среди обследованных нами пациентов лишь 2 имели ревматический компонент АПС, в 1 случае выявлены положительные АТ к миокарду, при отсутствии признаков воспалительного поражения миокарда по данным МРТ.

В лабораторных параметрах диагностики миокардита трудно выделить специфические маркеры. В основном используют общепринятые показатели воспалительного процесса - скорость оседания эритроцитов, СРБ, биомаркеры некроза (тропонин І, тропонин, КФК (особенно МВ-фракцию)), сердечной недостаточности (уровни натрийуретических пептидов). Дополнительно рекомендуется определение АТ к АГ миокарда В крови, специфичных для миокардита. У пациентов с миокардитом в настоящее время можно определять более 20 аутоантител к кардиальным и мышечным АГ ( $\beta 1$-адренорецепторам и холинергическим рецепторам, антимитохондриальные АТ, антисаркоплазматические AT, АТ к Са²+-АТФазе, антимикросомальные АT, АT к миофибриллам - актину и миозину, АТ к компонентам межклеточного пространства).

Их обнаружение может позволить диагностировать аутоиммунную причину заболевания, определить оптимальную тактику лечения [6-8, 10, 18]

В нашей работе при определении АТ к миокарду в 98\% случаев результат был отрицательным. Нами также проанализированы дополнительные показатели диагностики миокардита. Уровни КФК, СРБ, тропонина I и NT-proBNP могут свидетельствовать об отсутствии острого/хронического воспалительного процесса у обследуемой группы пациентов.

\section{Ограничения исследования}

К ограничениям в исследовании относится малое число обследованных пациентов с ревматоидными компонентами АПС. У данной когорты пациентов, возможно, имеется более частое поражение сердца. Также к ограничению исследования можно отнести отсутствие в протоколе эндомиокардиальной биопсии как наиболее надежного показателя наличия воспалительного процесса. Ограниченный объем выборки пациентов не позволил экстраполировать полученные данные на всю популяцию пациентов с АПС 2, 3 типов в РФ в целом.

\section{ЗАКЛЮЧЕНИЕ}

Пациенты с АПС взрослых начинают наблюдаться у эндокринолога в молодом или среднем возрасте. Необходимо учитывать потенциальную возможность развития у них аутоиммунного поражения миокарда, особенно при сочетании эндокринной и ревматологической патологии. По результатам нашей работы у пациентов с АПС 2 типа получены МРТ-данные, свидетельствующие о функциональных изменениях миокарда (91\% случаев). Аутоиммунная причина данных изменений по результатам определения АТ к миокарду не подтверждена у большинства обследованных пациентов. Положительный результат выявлен у 1 пациента (2\%), у которого имелось сочетание эндокринных (первичная ХНH, первичный гипотиреоз) и ревматологического компонентов (дерматомиозит) АПС. Ни в одном случае не выявлено одновременного повышения показателей «повреждения» миокарда (тропонин I и NT-proBNP), изолированно NT-proBNP был повышен у 14\% пациентов. Показатели КФК имели отклонение в 6\%, а СРБ - в 14\% случаев, при отсутствии признаков миокардита у пациентов по результатам МРТ. Таким образом, вопрос о необходимости проведения рутинного лабораторно-инструментального обследования сердечно-сосудистой системы у взрослых больных АПС при отсутствии клинических признаков поражения миокарда остается открытым и нуждается в дальнейшем изучении.

\section{ДОПОЛНИТЕЛЬНАЯ ИНФОРМАЦИЯ}

Источник финансирования. Грант РНФ № 17-75-30035 «Аутоиммунные эндокринопатии с полиорганными поражениями: геномные, постгеномные и метаболомные маркеры. Генетическое прогнозирование рисков, мониторинг, ранние предикторы, персонализированная коррекция и реабилитация»

Конфликт интересов. Авторы декларируют отсутствие явных и потенциальных конфликтов интересов, связанных с публикацией настоящей статьи.

Участие авторов. Трошина Е.А., Молашенко Н.В. - концепция и дизайн исследования; Молашенко Н.В., Бабаева Д.М., Малышева Н.М., Бостанова Ф.А. - сбор и обработка материала; Молашенко Н.В. написание текста; Трошина Е.А., Бабаева Д.М., Никанкина Л.В., Малышева Н.М. - редактирование.

Все авторы внесли значимый вклад в проведение исследования и подготовку статьи, прочли и одобрили финальную версию статьи перед публикацией.

\section{БЛАГОДАРНОСТИ}

Коллектив авторов выражает благодарность врачу-ревматологу ФГБУ «НМИЦ эндокринологии» Минздрава России Паневину Тарасу Сергеевичу за методическую помощь в работе, ООО «Центр лечения суставов и сердца», г. Москва, за проведение в лаборатории центра анализов на антитела IgG к антигенам сердечной мышцы. 


\section{СПИСОК ЛИТЕРАТУРЫ | REFERENCES}

1. Ларина А.А., Трошина Е.А., Иванова О.В. Аутоиммунные полигландулярные синдромы взрослых: генетические и иммунологические критерии диагностики // Проблемы эндокринологии. - 2014. - Т.60. - №3. - C. 43-52. [Larina AA, Troshina EA, Ivanova ON. Autoimmune polyglandular syndromes in the adults: the genetic and immunological diagnostic criteria. Problems of Endocrinology. 2014;60(3):43-52. (In Russ.)] doi: 10.14341/probl201460343-52.

2. Kahaly GJ. Polyglandular autoimmune syndromes. Eur J Endocrinology. 2009;161 (1):11-20. doi: 10.1530/eje09-0044.

3. Шульгина В.Ю., Фадеев В.В., Мельниченко Г.А. Поражения миокарда при тиреотоксикозе: особенности течения, исходы, отдаленный прогноз // Клиническая и экспериментальная тиреоидология. - 2006. - Т.2. — №4. - C. 21-30. [Shulgina VYu, Fadeyev V, Melnichenko GA. Myocardial lesion in hyperthyroidism: natural history, outcomes, prognosis. Clinical and experimental thyroidology. 2006;2(4):21-30. (In Russ.)].

4. Marvisi M, Brianti M, Marani G, et al. Hyperthyroidism and pulmonary hypertension. Resp Med. 2002;96(4):215-220. doi: 10.1053/rmed.2001.1260

5. Li JH, Safford RE, Aduen JF, et al. Pulmonary hypertension and thyroid disease. Chest. 2007;132(3):793-797. doi: 10.1378/chest.07-0366.

6. Моисеева О.М., Митрофанова Л.Б., Пахомов А.В., и др. Спорные вопросы диагностики миокардитов // Сердие: журнал для практикующих врачей. - 2010. - Т.9. - №4. - С. 234-241. [Moiseeva OM, Mitrofanova LB, Pahomov AV, et al. Spornyye voprosy diagnostiki miokarditov. Serdtse: zhurnal dlya praktikuyushchikh vrachey. 2010:9(4):234-241. (In Russ.)].

7. Дерюгин М.В., Бойцов С.А. Хронические миокардиты. - СПб.: ЭЛБИ-СПб, 2005. - 288 с. [Deryugin MV, Boytsov SA. Khronicheskiye miokardity. Saint Petersburg: ELBI-SPb; 2005. 288 p. (In Russ).]

8. Коваленко В.Н., Несукай Е.Г., Чернюк С.В. Миокардит: современный взгляд на этиологию и патогенез заболевания // Украинский кардиологический журнал. - 2012. - №2. C. 84-91. [Kovalenko VN, Nesukai YeG, Cherniuk SV. Myocarditis: a contemporary look on the etiology and pathogenesis of the disease. Ukrainskii kardiologicheskii zhurnal. 2012;(2):84-91. (In Russ.)]

9. Caforio AL, Goldman JH, Baig MK, et al. Cardiac autoantibodies in dilated cardiomyopathy become undetectable with disease progression. Heart. 1997;77(1):62-67. doi: 10.1136/hrt.77.1.62.

10. Полетаев А.Б. Новые подходы в раннем выявлении патологических изменений в организме человека (иммунохимический скрининг как основа стратегии перехода от лечебной к превентивной медичине). Методические рекомендации для врачей. 2-е изд. - М.: МИЦ Иммункулус,
2011. - 64 c. [Poletaev AB. Novyye podkhody v rannem vyyavlenii patologicheskikh izmeneniy v organizme cheloveka (immunokhimicheskiy skrining kak osnova strategii perekhoda ot lechebnoy k preventivnoy meditsine). Metodicheskiye rekomendatsii dlya vrachey. 2nd ed. Moscow: MIC Immunkulus; 2011. 64 p. (In Russ.)].

11. ACCF/ACR/AHA/NASCI/SCMR 2010 Expert Consensus Document on Cardiovascular Magnetic Resonance. J Am Coll Cardiol.2010;55(23):2614-2662. doi: 10.1016/j.jacc.2009.11.011

12. Sezai A, Hata M, Minami K. Hypertrophic obstructive cardiomyopathy with Schmidt's syndrome. Thorac Cardiov Surg. 2010;58(5):309-316. doi: 10.1055/s-0029-1185884

13. Nielsen TD, Steenbergen C, Russell SD. Nonischemic cardiomyopathy associated with autoimmune polyglandular syndrome type II. Endocr Pract. 2005;13(1):59-62. doi: 10.4158/EP.13.1.59.

14. De Giorgi A, Fabbian F, Tiseo R, et al. Takotsubo cardiomyopathy and endocrine disorders: a mini-review of case reports. Am J Emerg. Med. 2014;32(11):1413-1417. doi: 10.1016/j.ajem.2014.07.030

15. Cardiov KN, Chhabra L, Ahmad SA, et al. Case report: autoimmune polyglandular syndrome Type 2 complicated by acute adrenal crisis and pericardial tamponade in the setting of normal thyroid function. Methodist Debakey Cardiovasc J. 2015;11(4):250-252. doi: 10.14797/mdcj-11-4-250.

16. Campean R, Hasun M, Stöllberger C, et al. Takotsubo-like syndrome triggered by fludrocortisone overdose for Addison's disease: a case report. J Med Case Rep. 2016;10(1):281. doi: 10.1186/s13256-016-1074-5.

17. Мочула О.В. Магнитно-резонансная томография с контрастным усилением в оченке повреждения миокарда при некоронарогенных поражениях сердиа: Автореф. дис. ... канд. мед. наук. - Томск, 2017. - 27 c. [Mochula OV. Magnitno-rezonansnaya tomografiya skontrastnym usileniyem v otsenke povrezhdeniya miokarda pri nekoronarogennykh porazheniyakh serdtsa. [dissertation abstract] Tomsk; 2017. 27 p. (In Russ.)].

18. Диагностика и лечение миокардитов. Проект клинических рекомендаций // Евразийский кардиологический журнал. 2019. - №2. - C. 22-44. [Diagnosis and treatment of myocarditides. Draft clinical guidelines. Eurasian heart journal. 2019;(2):22-44. (In Russ.)].

19. Mavrogeni S, Markussis V, Bratis K, et al. Hyperthyroidism induced autoimmune myocarditis. Evaluation by cardiovascular magnetic resonance and endomyocardial biopsy. Int J Cardiol. 2012;158(1):166-168. doi: 10.1016/j.ijcard.2012.04.089.

20. Fatourechi V, Edwards WD. Graves' disease and low-output cardiac dysfunction: implications for autoimmune disease in endomyocardial biopsy tissue from eleven patients. Thyroid. 2000;10(7):601-605. doi: 10.1089/thy.2000.10.601.

Рукопись получена: 30.07.2020. Одобрена к публикации: 25.08.2020. Опубликована online: 30.09.2020.

\section{ИНФОРМАЦИЯ ОБ АВТОРАХ [AUTHORS INFO]}

* Молашенко Наталья Валерьевна, к.м.н., ведущий научный сотрудник отдела терапевтической эндокринологии ФГБУ «Национальный медицинский исследовательский центр эндокринологии» Минздрава России, Москва, Российская Федерация [Natalya V. Molashenko, MD, PhD]; адрес 117036, Москва, ул. Дмитрия Ульянова, д. 11 [address: 11 Dm. Ulyanova street, 117036 Moscow, Russia], ORCID: https://orcid.org/0000-0001-6265-1210; eLibrary SPIN: 5679-2808; e-mail: molashenko@mail.ru

Трошина Екатерина Анатольевна, д.м.н., профессор, член-корреспондент PAH [Ekaterina A. Troshina, MD, PhD, prof.]; ORCID: https://orcid.org/0000-0002-8520-8702; eLibrary SPIN: 8821-8990; e-mail: troshina@inbox.ru

Бабаева Диана Мажлумовна, врач-рентгенолог [Diana M. Babaeva, MD]; ORCID: https://orcid.org/0000-0002-2812-7017; eLibrary SPIN: 6431-9855; e-mail: dianababaeva1@yandex.ru

Малышева Наталья Михайловна, к.б.н. [Natalia M. Malysheva, PhD]; ORCID: https://orcid.org/0000-0001-7321-9052; eLibrary SPIN: 5793-2550, e-mail: natalya.m@list.ru

Никанкина Лариса Вячеславовна, к.б.н. [Larisa V. Nikankina, PhD]; ORCID: http://orcid.org/0000-0001-8380-3825; eLibrary SPIN:2794-0008, e-mail: larisa.nikankina@yandex.ru

Бостанова Фатима Аслановна, клинический аспирант [Fatima A. Bostanova, Research fellow]; ORCID: http://orcid.org/0000-0001-5824-9536; eLibrary SPIN: 4595-5832; e-mail: fabostanova@gmail.com 


\section{ЦИТИРОВАТЬ:}

Молашенко Н.В., Трошина Е.А., Бабаева Д.М., Малышева Н.М., Никанкина Л.В., Бостанова Ф.А. Инструментальнолабораторные показатели состояния миокарда у взрослых пациентов с аутоиммунным полигландулярным синдромом 2, 3 типов // Проблемы эндокринологии. — 2020. — Т. 66. — №4. - С. $16-23$. doi: https://doi.org/10.14341/probl12554

\section{TO CITE THIS ARTICLE:}

Molashenko NV, Troshina EA, Babaeva DM, Nikankina LV, Malysheva NM, Bostanova FA. Instrumental and laboratory parameters of myocardial function in adult patients with autoimmune polyglandular syndrome type 2, 3. Problems of Endocrinology. 2020;66(4):16-23. doi: https://doi.org/10.14341/probl12554 